\title{
Exploration and Practice of "Order Form" Talent Cultivating Pattern in University
}

\author{
Cheng Li, Le-le Si \\ Department of Management Eng., Business School, Shanghai DIANJI Univ., Shanghai, 201306, China
}

\begin{abstract}
The tough employment situation of college students and its reasons were analyzed. The features and effects of some typical talents cultivation model in both domestic and foreign universities were discussed. Based on that, an "Order Form" talent cultivating pattern aiming to increase the students' employment ability, tighten the cooperation between university and enterprise were proposed. The target and intention of this pattern were defined, and some key problems and solutions were discussed. And preliminary practice has been carried on, and positive results achieved.
\end{abstract}

Keywords-“Order Form" talent cultivating pattern; Employment rate; Professional match rate; Cooperation between university and enterprise; Education innovation

\section{高校订单式人才培养模式的探索与实践}

\author{
李成 司乐乐 \\ 上海电机学院商学院管理工程系, 临港新城, 浦东新区, 上海, 中国
}

摘 要 分析了当前大学生极其困难的就业形势及其内在的原因, 研究了国内外高校部分典型的人才培养模式的特点和效果。在 此基础上, 提出了一种面向就业能力培养的、校企合作的高校订单式人才培养模式, 明确了该培养模式的目标, 定义和分析了其内涵, 并进行了初步的实践, 对其中的一些关键问题及其解决思路进行了阐述, 初步的实践结果证明该培养模式取得了比较积极的成效。

关键词＼cjkstart订单式人才培养模式；就业率；专业对口率；校企合作；教学改革

\section{1. 大学生就业形势简述}

自 1999 年教育部出台《面向 21 世纪教育振兴行动计 划》[1], 全国高等普通高校每年招生平均录取率以近 5 个 百分点增长[2]。至 2014 年, 全国高校毕业生达已达 727 万, 而这些毕业生的就业情况却不容乐观。

根据 2014 年 4 月中旬的统计, 北京的毕业生签约率为 $28 \%$, 上海的毕业生签约率为 $29 \%$, 均不足三成。其中本 科毕业生仅有 17\%成功签约[3]。如进行更深层次的分析, 将发现以下问题:

1）专业对口率低。数据显示, 实现就业的大学毕业生 中, 仅有 $35.1 \%$ 的人从事的工作与所学专业有关, 但 $65 \%$ 受调查大学生表示首要打算找到与专业相关的工作 [4]。

2) 工薪待遇差。以上海为例, 目前大多数毕业生起薪 为 2500 , 很多岗位的工资都在 2000 元甚至 2000 元以下 [5]。

3) 企业难以找到符合要求的毕业生。企业花费大量人 力物力财力招聘大学生, 但效果不佳, 招进企业后难以快
速胜任企业工作。

从上述分析可以看出, 一方面大学毕业生大多还是愿 意从事本专业领域的工作, 但却难以在本专业领域找到合 适的工作, 也难以获得满意的薪资待遇; 另一方面, 企业 也难以招聘到真正满足需求的大学毕业生。

\section{2. 大学生就业难内在原因分析}

专家指出, 造成本科生就业难和专业对口率低的主要 原因, 就是一些地方本科院校的毕业生 “不接地气”, 学校 在教学中只强化专业理论知识, 没有按照企业的需要来对 接教学[6]。

以下从学校、企业和学生三方面来分析高校毕业生就 业难、专业对口率低的原因。

1）高校方面的原因。一方面, 高校在扩招过程中发展 失衡, 热衷圈地和参与大学城建设, 造成师资水平跟不上 高校在学校规模、新专业开设等方面的超常规高速发展, 
在人才培养上 “心有余力不足”。另一方面, 对就业市场的 变化缺乏了解, 专业培养方案与市场需求脱节。能随需而 变, 更不能培养出业内抢手的人才。同时, 多数高校从上 到下, 并没有真正为促进学生就业进行系统性的思考和作 为, 没有为构架起联系学校、学生、企业三者之间的有效 渠道, 导致学校不了解企业需求, 培养方案与社会脱节; 学生渴望了解企业, 却苦无门路; 企业方面不了解学校的 培养模式与内容、不了解学生的总体素质, 对于高校人才 培养模式颇多质疑。

2）学生方面的原因。学生对于本专业认知错位、缺乏 就业意识, 在专业学习中被动消极, 没有培养出良好的专 业素质。临近就业时, 迫于严峻的就业形势, 只好抱着 “先 择业、后就业” 的心态, 先找到 “保底” 却未必是自己所 学专业的工作。此外, 学生掌握的知识陈旧, 转化率低也 是企业着重反馈的原因。

3) 企业方面的原因。在大学生培养过程中缺位, 对工 作岗位以及专业实践经验的要求没有传递到学生的在校培 养中。企业没有参与高校的人才培养过程, 招聘过程带有 强烈 “投注式” 色彩的, 企业需求难以从根本上得到保证。 另外, 企业往往要求具备专业实践经验, 也给亟待就业的 大学生带来巨大的压力。

综上所述, 校、企、学生等各方面的多种原因交织在 一起, 造成了目前大学生专业能力差, 导致就业难、专业 对口率低的现状。

\section{3. 国内外高校人才培养模式比较分析}

高校作为培养学生, 向企业输送人才的 “中转枢纽”, 应该对解开大学生就业难的困局负有首要责任。高校必须 主动反思学生培养过程中的不足, 积极探索能够适应目前 我国双向选择的就业机制和人才供过于求的就业形势的人 才培养模式, 提高毕业生就业竞争力。

笔者比较研究了部分成功的国内外高校人才培养模 式, 发现仍存在不足之处。如德国 “慕尼黑就业模式” [7] 比较依赖政府机构的控制, 缺乏自主性; 英国 BETC(Business \& Technology Education Council)模式[8]侧 重于对学生的能力培养, 但没有为学生明确地指出就业渠 道, 不能确保每一位学员的就业质量; 新加坡的 “教学工 厂” 培养模式[9]仍以学院为本位, 如果套用在中国高校专 业人才培养模式上, 不足以应对目前中国庞大的待就业毕 业生群的; 加、美的 CBE(Competency Based Education)[10] 教学模式则有专业上的局限性, 并且会使毕业生缺乏就业 弹性和适应性[11]; 国内的校企合作模式[12]尚停留在表 面, 存在着特色不强, 层次不清的问题, 加上有针对性的 训练不够, 学生接触不到很多实际的训练, 动手能力比较
差, 对于带动学生就业, 提高就业的专业对口率, 培养学 生就业竞争力尚未起到突出作用。

所以, 需要在充分理解上述培养模式、成效及其社会 环境的基础上, 深入研究我国高校人才培养、企业需求和 社会就业的实际情况, 特别是各个高校应利用 SWOT 等方 法深刻分析自身优势、劣势、机遇和挑战, 提出针对性的 解决方案, 建立起具体化、明确化、制度化的解决措施, 真正改变大学生就业难的局面。

\section{4. 订单式培养模式的概念及内涵}

综上所述, 针对目前大学毕业生就业率低、专业对口 率更低的困局, 必须对高校人才培养模式进行改革和创新, 切实提高学生专业能力和就业竞争力。

为此, 笔者根据我国高校和就业市场的具体情况, 提 出了一种面向就业能力培养的、校企合作的订单式人才培 养模式。

\section{1 订单式培养模式的概念}

订单式培养模式源于国外的 Cooperative Education, 即 “合作教育”[13]。其核心内容就是重视提高学生实践能力、 教学必须适应现实需求以及面向就业等。

我们所提出的订单式培养模式是在还原 Cooperative Education 本质的基础上, 以社会和企业需求为导向, 以能 力培养为本位, 培养有技术专长、有核心就业竞争优势的 应用型、技术型人才。

\section{2 订单式培养模式的内涵}

订单式人才培养模式是针对高校教育与市场需求脱节 的现象提出的, 因此, 它以社会和企业需求为导向, 以广 泛、密切的校企合作为前提, 以创新、柔性的培养方案为 基础, 以完善的契约为保障。消除传统人才培养模式的弊 端, 充分满足企业对于各类技能型、应用型人才的需求, 形成良性的人才培养氛围, 推动高等教育培养模式的改革。

\section{5. 订单式培养模式的初步实践}

如上所述，依托笔者所在高校 “技术立校、应用为本” 的办学定位, 我们在质量管理工程专业进行了订单式人才 培养模式的初步实践。对实践过程中的关键措施简述如下。

\section{1 实施前提}

首先, 花大力气建立订单式人才培养的合作企业群体。 初期的目标企业是现有的校外实习基地、科研合作企业、 前来学校招聘的企业, 此外应积极走访往届学生的就业单 位, 从中优选较长期内有稳定人才需求的企业, 就合格毕 
业生的培养模式与企业交流, 说服他们参加到订单式人才 培养计划中来。

之后, 要不遗余力的扩大参加该计划的企业数量, 同 时提高参与企业的质量。

\section{2 基础工作}

\section{1) 细化培养目标}

进一步明确专业的培养方向, 比如本专业原来的培养 定位是 “培养理论基础扎实、应用能力突出、能适应工作 变化并具有创新素质; 解决实际质量问题的应用型质量工 程技术人才”。这些还是有点笼统, 需要进一步明确本专业 毕业生就业有哪些主要的企业类别, 都需要哪些必要的和 特定的理论知识和技术技能。在此基础上, 才能细化培养 目标、进而调整课程体系与之相匹配。

\section{2) 教学课程体系模块化}

在培养课程体系设置方面, 要按照学科专业的要求, 对学科基础课、专业课进行仔细研究, 形成模块化。其中, 必修课要满足学科专业培养大纲的基本要求, 选修课则要 能够适应不同企业的培养需求。每一个学生的学习科目要 根据其个人兴趣、自我发展规划以及所参加的订单式培养 计划进行不同的选择。

针对企业特定的、不在专业现行课程目录中的技术技 能培养要求, 一是在校内跨专业、甚至跨学院解决; 二是 校企合作开发, 即由企业或校方专业教师为学生增设专门 的课程, 如质量控制技术、检测技术、可靠性试验技术等。 也可以邀请企业的专家给学生开设有学分的系列专题讲 座, 讲授最新的业务知识和技术。

3) 师资队伍和保障机制建设

如前所述, 按照订单式培养模式, 同一个专业的学生, 其学习科目、特别是技能培训可能有相当的差异, 其教学 及管理工作必然要复杂得多, 这就要求师资队伍和保障机 制建设等必须与之相适应。

\section{4) 实验与实习环境建设}

由于订单式培养模式特别强调面向用人单位和就业能 力的培养, 而校内的实验与校外的实习环境是实现这一目 标的关键, 所以要积极申请、利用各种计划的支持逐渐建 立完善的校内实验环境, 甚至校企双方在校内共建联合实 验室; 与合作企业商谈, 建立完备的校外实习基地以及实 习内容。

同时, 鼓励、提倡参加订单式培养计划的学生, 以企 业研发、生产经营中的实际问题为论文研究背景和对象撰 写毕业论文, 培养学生发现、解决工程实际问题的能力。

\section{3 培养计划及其实施}

1) 组建联合培养指导小组

落实校企合作的订单式培养模式的一个关键差异在于, 培 养方案及考核评价工作不再由学校单方面承担, 而是应该 由校企双方在专业培养大纲的基础上共同承担。

具体的方式可以组织专业的资深教师和企业方面的专 家联合组成的专业培养指导小组, 主要任务有两个: 一是 共同制定并及时修订适应企业需求的人才培养计划; 二是 对教学质量进行评估检查。

2）联合制定个性化、订单式的培养方案

由联合培养指导小组, 根据社会经济发展需要、企业 岗位需求, 制定工程技术人才的培养目标、培养方案、培 养计划, 并确定相应的知识需求, 以便将岗位知识需求转 化为专业培养目标, 并在课程设计中体现出来。

3) 学生实习计划

在与合作企业充分讨论的基础上, 设计了一个循序渐 进的入企实习计划, 如表 1 所示。

表 1 订单式培养学生实习计划

\begin{tabular}{|c|c|c|c|}
\hline $\begin{array}{ll}\text { 时 } & \text { 间 } \\
\text { 点 } & \end{array}$ & 时长 & $\begin{array}{l}\text { 实习 } \\
\text { 类型 }\end{array}$ & 工作目的及内容 \\
\hline $\begin{array}{c}\text { 大一 } \\
\text { 暑假 }\end{array}$ & $\begin{array}{l}1 \text { 个 } \\
\text { 月 }\end{array}$ & $\begin{array}{l}\text { 认知 } \\
\text { 实习 }\end{array}$ & $\begin{array}{l}\text { 了解企业的历史、文化、组织结构、 } \\
\text { 产品系列; 了解未来的工作性质, } \\
\text { 所需的知识结构 }\end{array}$ \\
\hline 大二 & $\begin{array}{l}2 \text { 个 } \\
\text { 月 }\end{array}$ & $\begin{array}{l}\text { 初级 } \\
\text { 实习 }\end{array}$ & $\begin{array}{l}\text { 在企业相关岗位轮岗, 熟悉相关工 } \\
\text { 作及专业知识 }\end{array}$ \\
\hline 大三 & $\begin{array}{l}2 \text { 个 } \\
\text { 月 }\end{array}$ & $\begin{array}{l}\text { 中级 } \\
\text { 实习 }\end{array}$ & $\begin{array}{l}\text { 定岗工作, 担任助手, 协助实际工 } \\
\text { 作 }\end{array}$ \\
\hline $\begin{array}{l}\text { 第 } 8 \\
\text { 学期 }\end{array}$ & $\begin{array}{l}5-7 \text { 个 } \\
\text { 月 }\end{array}$ & $\begin{array}{l}\text { 毕业 } \\
\text { 实习 }\end{array}$ & $\begin{array}{l}\text { 在企业导师的指导下, 负责实际工 } \\
\text { 作。并以企业真实的工程问题为背 } \\
\text { 景进行毕业论文 }\end{array}$ \\
\hline
\end{tabular}

该计划对学生而言, 可以使其较长期的实际参加企业 生产实践, 不仅加强技术技能培养训练, 也能不断了解企 业、认识企业, 促使其反过来认识专业, 明确学习目的、 增强学习动力, 最终成长为一个有较强就业竞争优势的工 程技术人才, 实现对口就业。对于企业而言, 有一个较长 期的观察、了解学生素质和工作能力的机会, 可以准确的 识别出真正满足企业需求的学生, 极大地节约了培养成本 和时间, 有助于尽快缔造稳定的技术骨干队伍, 提高员工 的忠诚度和归宿感, 增强企业凝聚力和活力。

这种实习机制能实现学生、企业和学校的 “三赢” 效 果, 从而良性循环, 为校企合作提供稳定的合作基础。

4）师资队伍建设

推行订单式培养模式必须具备良好的师资队伍建设和 相应的保障机制匹配。 
担任教学任务的教师应为复合型、双师型, 既要有较 高的专业理论, 又要有较强的实践工程经验。实践经验欠 缺的教师要通过科研、到企业挂职等多种方式, 提高实践 能力和技术应用水平。

同时校方也可以聘任企业推荐的高级技术人员、管理 人员为双师型兼职教授、副教授、讲师，为学生开设应用 型课程, 讲授应用性技术知识, 直接参与校方的理论教学、 实践教学、实训指导、论文指导、教材编写等教学活动。

5) 拓展校企科研合作空间

除了上述订单式培养的核心内容以外, 校企合作还有 很多拓展空间和潜力可以发掘。比如: 建立高水平的、示 范性的校外实习基地，企业可以聘任校方教师担任企业技 术顾问，为企业提供技术咨询、技术研发等服务，解决相 应的技术问题；企业也可作为校方教师企业挂职基地，以 增进双方合作关系, 加强理论教学与实际应用的联系; 建 立合作实验室,不仅为联合培养计划提供必要的教学实验 环境, 还可以就企业、行业的实际问题开展科研、联合申 报有关的国家及省部级科技计划项目等。

6）管理与评价

在订单式培养过程中, 校企双方必须密切联系, 共享 信息资源、人力资源和物质资源。及时反馈相关信息,共同 对教学过程、人才质量进行监控和评价, 有不足之处及时调 整,力求人才质量不断提高。

\section{6. 总结}

校企合作订单式人才培养模式的初步实践, 已经在毕 业生的就业率和专业对口率等方面取得了明显的改善。据 5 月初的统计, 2014 届质量管理工程专业的 45 位毕业生已 实现 $100 \%$ 就业, 同时用人单位对本校订单式人才也给予了 高度的肯定。

尽管如此, 仍需要进行一系列的研究、实践、完善工作, 包括:

1) 深入研究国家的相关政策要求, 特别是卓越工程师计 划的内涵, 满足国家、社会、企业等各方面对高等教 育改革的期望;

2) 进一步完善订单式培养模式的培养方案、计划;

3) 要取得更好的效果, 就必须花大力气加强校企合作的 深度与广度, 如果能够吸引更多更强的企业参与进来, 则可以从就业需求层面根本性的保证订单式培养模式 的成功;
4) 完善校企合作订单式培养模式中的法律问题，协议的 相关三方学校、学生、企业的责权, 特别是违约责任 要具体而明晰, 充分保证各方的权益, 避免产生纠纷; 研究在更大的专业范围内开展校企合作订单式培养模 式的可行性。

\section{参考文献}

[1] China's Ministry of Education. 21st Century Education Revitalization Action Plan. China Higher Education. march 1999.

[2] Tan Ye. Should Stop University Enrollment Expansion. Times Figure, 5 June 2013

[3] Ruo Li. Shanghai University Graduates Reached 178,000 in 2014. www.Xinmin.com, 27 March 2014

[4] MyCOS Research Institute. Employment "Utopia"--2014 graduates expect job analysis. 23,October 2013.

[5] Lin Lu. Shanghai university graduates signing rate is less than $30 \%$ and fair salary is for more 2500RMB. www.Eastday.net, 21 April 2014.

[6] Chuanfeng Dong. Many Municipal Colleges Brewing Transformation. The Morning News, 2014.3.26.

[7] Kai Wang. The Reflections on the cooperation between university and enterprise. Chinese Teachers. 2008(S1).

[8] Hong Zhu. The Enlightenment of Munich Employment Model. China University Students Career Guide. 2002(9).

[9] Riqiang Huang, Zhijun Deng. The Introduction of British Vocational Education into China", Studies In Foreign Education, 2004,31(5),p.52-55.

[10] Jing Tian, Fujun Liu and Ruiying Yang. Comparison of several talent cultivation models of advanced vocational education of foreign countries. Adult Education. 2007, (4), p94-96.

[11] Chongmei Guan, Zhiying Xu and Yufeng Liu. Exploration and Practice of localization of CBE education. Vocational \& Technical Education Forum. 2004, (6), p13-15

[12] Han Jianhai, Ma,Weiling Tan Cheng, etal. The construction of a new talent cultivating pattern based on cooperation and interaction between university and enterprise in the whole education process. China Electric Power Education. 2010, (32), p20-21.

[13] Li Quan. The foreign students' employment patterns and the enlightenment to China's university employment work. Beiing Education(Higher Education). 2007,(3), p62-64. 